\title{
Optimalisasi Internet Hotspot Menggunakan User Manajemen Pada Pusat Pengembangan SDM Asuransi Indonesia
}

\author{
Suryanto $^{1}$, Fitrah Agus Permadi ${ }^{2}$ \\ ${ }^{1}$ Program Studi Teknik Elektro Universitas Bina Sarana Informatika \\ e-mail: suryanto.syt@bsi.ac.id \\ ${ }^{2}$ STMIK Nusa Mandiri Jakarta \\ e-mail: fitrahpermadi@gmail.com

\begin{tabular}{ccc}
\hline Diterima & Direvisi & Disetujui \\
$10-12-2019$ & $13-12-2019$ & $17-12-2019$ \\
\hline
\end{tabular}

\begin{abstract}
Abstrak - Penggunaan layanan wireless internet sudah menjadi kebutuhan bagi pengguna yang berada dia area fasilitas umum dan perkantoran, sehingga menyediakan layanan tersebut sudah menjadi keharusan bagi sebuah Aula serbaguna. Namun demikian tidak menentunya jumlah pengguna yang terhubung pada layanan tersebut menjadi permasalahan bagi kualitas layanan baik berupa koneksi yang sering terputus, lambat dan sebagainya. Penerapan fasilitas plugin dari router mikrotik yaitu Mikrotik Userman diharapkan dapat menjadi solusi permasalahan layanan internet hotspot di Aula Pusat Pengembangan SDM Asuransi Indonesia. Dengan dibuatnya manajemen pengguna layanan hotspot dengan metode dan aturan yang ditetapkan maka secara otomatis mengatur akses internet setiap pengguna yang terhubung, seperti sistem keamanan layanan wireless internet yang disediakan, adanya grup pengguna dengan setiap grup dapat dibuat ketentuan yang berbeda seperti batas waktu koneksi, maksimum besaran bandwidth bahkan dapat memblokir layanan tertentu. Hasil dari implementasi user manajemen pada jaringan wireless layanan internet di Aula Pusat Pengembangan SDM Asuransi Indonesia dapat memberikan koneksi internet layanan internet yang optimal.
\end{abstract}

\begin{abstract}
The use of wireless internet services has become a necessity for users who are in the area of public facilities and offices, so providing these services has become a necessity for a multipurpose hall. However, the uncertainty number of which connected to the service is become a problem for the quality of service in the form of connections that are often lost, slow and so on. The application of the plugin facility from the proxy router, Mikrotik Userman, is expected to be a solution to the problem of internet hotspot services in the Hall of the Pusat Pengembangan SDM Asuransi Indonesia. With the hotspot service user management made with the methods and rules set it automatically regulates the internet access of each connected user, such as the wireless internet service security system provided, the existence of user groups with each group can be made different conditions such as connection timeout, maximum amount bandwidth can even block certain services. The results of the implementation of user management on wireless internet service networks in the Hall of the Pusat Pengembangan SDM Asuransi Indonesia can provide optimal internet service internet connections.
\end{abstract}

Keyword : Mikrotik, User management, Hotspot

\section{PENDAHULUAN}

Kebutuhan akan ketersediaan internet saat ini sangat tinggi dengan meningkatnya ketergantungan manusia akan peranan teknologi informasi. Hal tersebut mempunyai dampak diperlukan adanya sistem penyediaan layanan internet yang efisien, handal namun tetap ekonomis. Pamungkas (2016:17)

Begitu juga pada Aula Pusat Pengembangan SDM Asuransi Indonesia, sebagai aula serbaguna yang dimiliki dan dikelola oleh Asosiasi Asuransi Umum Indonesia, dimana aula ini utamanya digunakan untuk pelatihan Tenaga Asuransi, sertifikasi Agen Asuransi, Seminar dan berbagai kegiatan lainnya. Dalam rencana meningkatkan pelayanan serta permintaan dari sebagian besar pengunjung yang selalu menanyakan koneksi WIFI maka pengelola menyediakan fasilitas layanan internet berbasis wireless. Setelah berjalannya fasilitas ini, ternyata banyak komentar yang diterima oleh pengelola bahwa internet sangat lambat dan terkadang sulit untuk masuk kedalam wifi meskipun pihak manajemen telah melakukan penambahan bandwidth paket langganan namun fasilitas ini menjadi tidak maksimal dan dirasa perlu untuk dilakukan perbaikan.

Dari permasalahan ini, maka dibutuhkan user manajemen dan manajemen bandwidth dalam pengembangan Jaringan di Aula Pusat Pengembangan SDM Asuransi Indonesia guna optimalisasi performa jaringan dan koneksi yang 
tersedia. Pada penelitian ini bandwidth menjadi penting, menurut Sora N (2015) dalam Ardiansa Eko et al., (2017:1229) "Bandwidth adalah suatu nilai konsumsi transfer data yang dihitung dalam bit/detik atau yang biasanya di sebut dengan bit per second (bps), antara server dan client dalam waktu tertentu. Atau bisa didefinisikan sebagai lebar cakupan frekuensi yang dipakai oleh sinyal dalam medium transmisi”. Kapasitas bandwidth yang tersedia, dapat dilakukan pembagian pada masing-masing pengguna melalui manajemen bandwidth pada router, Manajemen bandwidth berperan dalam menentukan skala prioritas pengguna. Pada saat ada pengguna yang mengakses internet dengan kapasitas bandwidth yang lebih besar, maka kondisi tersebut tidak akan tergangu pengguna yang lain, karena setiap pengguna sudah mempunyai kapasitas bandwidth dan skala prioritas masing-masing pada jaringan internet yang digunakn. Akan tetapi, skala prioritas seringkali diabaikan oleh para administrator jaringan (Ambarwati, Saniya, \& Priyono, 2013).

Perlunya menerapkan ketentuan penggunaan internet untuk mendapatkan layanan internet yang tepat guna, aman dengan pembagian servis yang merata pada setiap pengguna yang terhubung untuk menjaga layanan tetap stabil.

Pengaturan bandwidth ini adalah salah saru cara yang diperlukan untuk melakukan optimalisasi data agar terdistribusi dengan merata sehingga setiap user yang terhubung mendapatkan nilai optimal.

Menjadi catatan bagi penulis adalah banyaknya jumlah user yang mengakses hotspot tersebut dengan bebagai karakter user, dimana semakin banyak user yang terhubung akan semakin besar memakan bandwidth serta mengakibatkan terjadinya gangguan koneksi. Mengacu kepada kondisi tersebut, penulis mencoba mencari referensi dari berbagai sumber terkait dengan metode yang cocok untuk digunakan pada kondisi tersebut, dan menemukan metode Peer Connection Queue (PCQ) sebagai metode yang cocok untuk digunakan.

Seperti disampaikan oleh Rifai (2017:74) "Penerapan management bandwidth dengan algoritma Per Connection Queue pada sebuah jaringan merupakan cara yang terbaik untuk menangani jaringan yang jumlah clientnya berubah secara dinamis atau tidak tetap".

Dengan algoritma Peer Connection Queue (PCQ) ini penulis melihat adanya kesesuaian kondisi dilokasi penelitian dimana jumlah client tidak dapat diperkirakan setiap harinya, sehingga menganggap algoritma ini dapat diterapkan pada Gedung Pusat Pengembangan SDM Asuransi Indonesia.

\section{Konsep Dasar Jaringan}

Dapat dijelaskan bahwa jaringan komputer adalah kumpulan beberapa komputer (dan perangkat lain seperti Router, Swicth, dan sebagainya) yang saling terhubung satu sama lain melalui media perantara. Media perantara ini bisa berupa media kabel ataupun media tanpa kabel (nirkabel). Informasi berupa data akan mengalir dari satu komputer ke komputer lainnya atau dari satu komputer ke perangkat yang lain, sehingga masingmasing komputer yang terhubung tersebut bisa saling bertukar data atau berbagi perangkat keras. Sofana (2013:3)

\section{Wireless Fidelity (WIFI)}

Perkembangan teknologi dalam Jaringan Komputer sudah berkembang, dimana komunikasi antar komputer/perangkat yang semula dihubungkan melalui media Kabel saat ini telah berkembang menggunakan jalur Gelombang Frekuensi/Nirkabel.

Disampaikan oleh Doni (2014:37). "Dengan adanya perkembangan teknologi yang pesat, secara perlahan membutuhkan teknologi yang melibatkan jaringan komputer lokal tanpa kabel (wireless). Perkembangan tidak berhenti sampai disitu, berbagai ide dan teknik baru bermunculan untuk mempermudah penggunaan sistem pada internet. Sehingga penggunanya tidak hanya terbatas pada sistem kabel saja, akan tetapi berkembang menjadi sebuah jaringan wireless yang dapat diakses oleh seluruh pengguna yang membutuhkan akses internet".

Sambungan tanpa kabel tersebut saat ini dikenal dengan istilah WIFI, Menurut Sofana (2013:334) "WI-FI atau WIFI merupakan singkatan dari Wireless Fidelity, merupakan nama lain untuk produk-produk spesifikasi 802.11 yang dibuat oleh Wi-Fi Alliance. Pertama kali kemunculan sejak ditemukannya WIFI tahun 1997”.

Dengan teknologi ini pengguna dapat meghubungkan perangkatnya kedalam jaringan wireless tersebut melalui gelombang frekuensi untuk mendapatkan layanan internet tanpa lagi harus menggunakan kabel.

\section{Wireless Network}

Menurut Primartha, (2019:46) dalam jurnalnya mengatakan bahwa: "Wireless network adalah jaringan yang menggunakan media penghantar gelombang radio atau cahaya untuk mentransmisikan data. Frekuensi gelombang radio yang digunakan untuk jaringan komputer biasanya berkisar antara $2.4 \mathrm{GHz}$ dan $5.8 \mathrm{GHz}$."

\section{Hotspot}

Untuk dapat mengakses fasilitas wifi tadi dalam sebuah area yang dikenal istilah Hotspot, dimana dalam area hotspot ini tersedia layanan jaringan nirkabel untuk mengakses layanan internet.

Menurut Sofana (2013:343) "Hotspot atau Area Hotspot adalah tempat khusus yang disediakan untuk mengakses Internet menggunakan peralatan 
Wi-Fi. Umumnya layanan Hotspot bersifat gratis. Dengan berbekal laptop atau PDA maka koneksi Internet dapat dilakukan secara cuma-cuma.

Biasanya pengguna terlebih dulu harus melakukan registrasi ke penyedia layanan hotspot untuk mendapatkan Login dan Password. Proses otentikasi dilakukan ketika browser diaktifkan".

\section{Hotspot Server}

Untuk mengoptimalkan proses pengaturan bagi area yang menggunakan beberapa akses point perlu dibuat Hotspot server yang berfungsi menetapkan aturan yang sama untuk setiap perangkat akses point menjadi sebuah layanan hotspot.

Menurut Rifai \& Sudibyo (2018:112) "Hotspot server merupakan konsep akses internet dengan menggunakan authentication pada halaman web untuk sisi keamanan, setiap user akan diberikan akses sesuai dengan aturan yang berlaku berupa username dan password sehingga setiap user hanya bisa menggunakan username sesuai ketentuan dan jika username dan password yang digunakan tidak sesuai atau valid makan user tersebut tidak dapat menggunakan akes internet yang diberikan".

"Untuk membangun Hotspot Server ada beberapa parameter dan service yang harus digunakan seperti DHCP Server berfungsi untuk memberikan ip address kepada user ketika terhubung ke Server Hotspot, NAT Firewall untuk melakukan masquerade. Web Proxy berfungsi menampilkan halaman login saat user melakukan authenticaton pada hotspot server, firewall filter digunakan untuk memblokir user yang tidak sesuai dengan authentication. Firewall mangle digunakan untuk melakukan marking packet yang masuk dan keluar pada user, simple queue digunakan untuk alokasi bandwidth yang aka diberikan pada user baik upload dan download. Rifai \& Sudibyo, (2018:113)

\section{Mirotik Routerboard}

Menurut Pamungkas (2016:19) "Mikrotik routerboard merupakan sebuah perangkat jaringan komputer yang menggunakan Mikrotik RouterOS yang berbasis Linux dan diperuntukkan bagi network router. Mikrotik routerboard memiliki beberapa fasilitas seperti bandwith management, stateful firewall, hotspot for plug and play access, remote Winbox GUI admin, dan routing".

\section{Manajemen Jaringan}

Menurut Alexander Clemm dalam buku Primartha (2019:8) bahwa "Manajemen jaringan merupakan sebuah aktifitas, metode, produser dan alat yang berhubungan dengan operasional, administrasi, perawatan, dan penyediaan system jaringan".
Primartha (2019:8) dalam bukunya menyebutkan terdapat 4 metode sebagai berikut:

\section{a. Operations}

Operations berkaitan dengan bagaimana menjaga agar network (dan juga servis yang disediakan) tetap berjalan secara mulus. Operations terkait dengan monitoring network untuk mengetahui adanya masalah dan mengatasi masalah secepat mungkin. Idealnya pengguna tidak sampai mengetahui dan merasakan dampak dari masalah ini.

\section{b. Administration}

Berkaitan dengan bagaimana menjaga sumber daya (resources) jaringan dan bagaimana mengkonfigurasinya dengan benar agar tetap terkendali. Administration berhubungan dengan pekerjaan rutin atau harian.

\section{c. Maintenance}

Berkaitan dengan aktifitas perbaikan dan upgrade. Misalnya mengganti kabel yang rusak, upgrade protocol, patch, pada firewall, dan sebagainya. Maintenance juga terkait dengan tuning, udjusting device parameter, sehingga network dapat berjalan lebih baik.

\section{d. Provisioning}

Berkaitan dengan konfigurasi sumber daya dalam jaringan untuk mendukung layanan yang diberikan. Misalnya, melakukan pengaturan jaringan sehingga pelanggan baru dapat menerima layanan voice.

\section{Manajemen Bandwidth}

Besarnya kapasitas bandwidth yang dimiliki tentu bukan jaminan bahwa koneksi akan tetap lancer dan stabil karena bandwidth ini akan terbagi secara otomatis tergantung dengan banyaknya pengguna yang mengakses, dimana semakin banyak pengguna yang menggunakan jaringan tersebut bandwidth akan semakin berkurang dan tapa adanya pengaturan yang baik maka pembagian menjadi tidak merata.

Menurut Athailah (2013:94) "Manajemen Bandwidth atau Bandwidth Management System (BMS) adalah sebuah metode yang diterapkan untuk mengatur besarnya bandwidth yang akan digunakan oleh masing-masing user di sebuah jaringan sehingga penggunaan bandwith akan terdistribusi secara merata."

\section{METODE PENELITIAN}

Metode yang digunakan dalam penelitian ini adalah metode eksperimental. Menurut Sugiyono (2013), "Metode eksperimen termasuk dalam metode kuantitatif yang dilakukan di 
laboratorium dengan adanya perlakuan (treatment). Metode eksperimen dapat diartikan sebagai metode penelitian yang digunakan untuk mencari pengaruh perlakuan tertentu terhadap yang lain dalam kondisi yang terkendalikan". Metode eksperimen ini meliputi studi literatur, analisa, perancangan, implementasi, pengujian sistem, evaluasi dan dokumentasi. Dalam melakukan penelitian ini penulis melakukan pengumpulan data sebagai dasar mendapatkan solusi yang tepat gna menyelesaikan permasalahan diatas, adapun metode pengumpulan data yang dilakukan adalah:

a. Observasi

Metode pengamatan langsung / Observasi pada gedung Pusat Pengembangan SDM Asuransi Indonesia mulai tanggal $03 \mathrm{~s} / \mathrm{d} 15$ Maret 2019, pengamatan yang dilakukan terkait skema jaringan, jenis layanan yang dipakai, kualitas koneksi dan jumlah pengguna.

b. Wawancara

Dalam penelitian ini penulis tidak melaksanakan metode wawancara pada setiap pengguna yang menggunakan fasilitas internet hotspot tersebut, dimana penulis hanya menerima keluhan yang diterima oleh manager Aula dari tamu yang menggunakan Aula tersebut yang disampaikan secara lisan.

c. Studi Pustaka

Sebagai bahan referensi untuk pemecahan masalah tersebut penulis mencoba menggunakan metode literature dimana mencari sumber referensi dari Jurnal, Karya Ilmiah serta bukubuku terkait dengan jaringan melalui berbagai sumber baik dokumen digital maupun dokumen cetak

Sedangkan untuk mengembangkan sistem ini peneliti menggunakan model pengembangan sistem NDLC (Network Development Life Cycle) yang terdiri dari 6 tahap, yaitu analisis, desain, simulasi, monitoring, implementasi, dan manajemen (P. Rawles and J.E. Goldman: 2004)

\section{HASIL DAN PEMBAHASAN}

Untuk pemecahan masalah pada jaringan kantor sekretariat Aula Pusat Pengembangan SDM Asuransi Indonesia (AAUI) dilakukan beberapa. pengaturan tersebut antara lain melakukan manajemen bandwidth, melakukan manajemen pengguna serta membuat aturan pembatasan Hak Akses. Dimana dengan dilakukannya langkah ini maka penggunaan layanan wireless jadi lebih terkontrol dan termonitor sehingga dapat menghasilkan koneksi yang lebih maksimal.

Untuk melakukan langkah tersebut diperlukan penggantian perangkat router yang memiliki kemampuan lebih baik sebagai perangkat yang akan menjalan setiap aturan yang dibuat secara otomatis dan menjadi pusat kontrol bagi jaringan dikantor sekretariat AAUI. PEngaturan ini dapat dilakaukan dengan Router Mikrotik yang dapat memanajemen jaringan yang lebih baik, menambah sistem keamanan jaringan dan membuat pemakaian internet menjadi maksimal.

Untuk lebih mengoptimalkan layanan internet Kantor Sekretariat AAUI maka perlu juga dibuat ketentuan atau aturan internal kantor sekretariat AAUI terkait dengan penggunaan internet pada jam kantor. Dimana ketentuan atau aturan inilah yang menjadi dasar nantinya akan dimasukan kedalam konfigurasi di Router dan akan berjalan secara otomatis.

\section{Topologi Jaringan}

a. Topologi jaringan awal

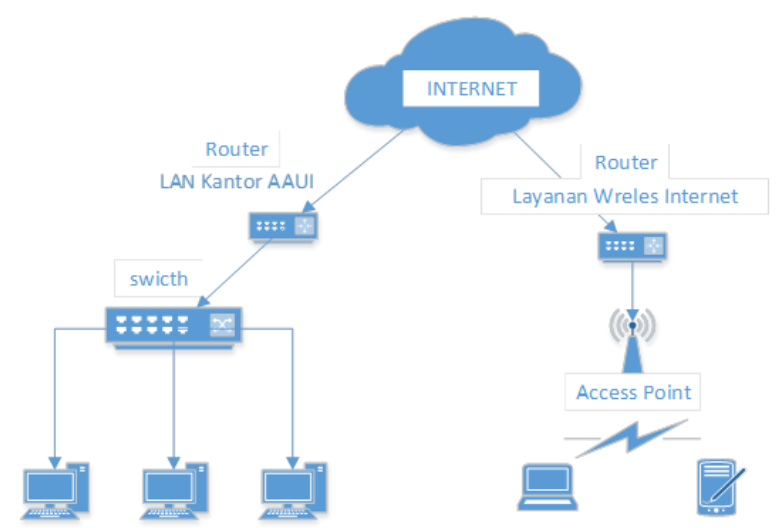

Sumber: Suryanto (2019).

Gambar 1. Topologi jaringan awal

Melihat topologi diatas, tidak banyak dilakukan perubahan terhadap topologi awal, jenis topologi tetap menggunakan type topologi star dengan menggunakan type koneksi peer to peer. Penggantian perangkat jaringan (Router) yang sebelumnya 2 unit menjadi 1 unit dan tetap berfungsi sebagai DNS Server namun perbedaannya Router inilah yang juga berfungsi sebagai perangkat manajemen pada layanan Internet Hotspot di Aula Pusat Pengembangan SDM Asuransi Indonesia yang akan menjalankan aturan/ketentuan yang telah dibuat sesuai dengan yang ditetapkan oleh perusahaan. 
b. Rancangan Topologi Akhir

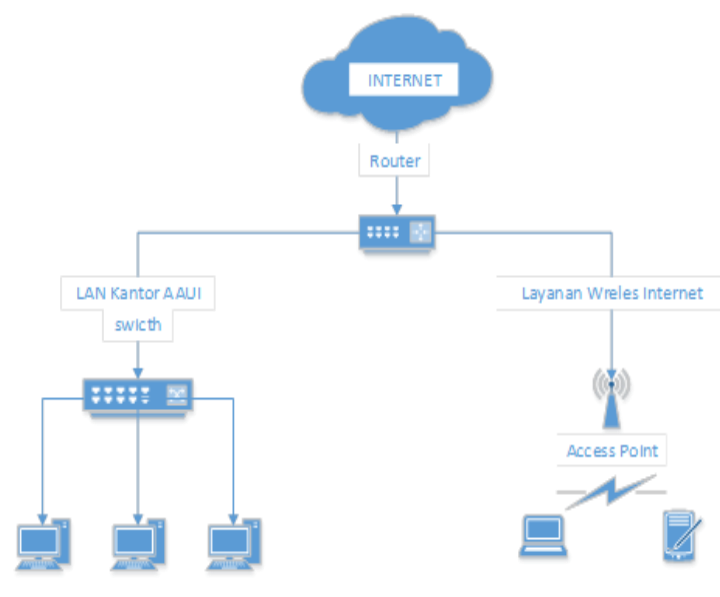

Sumber: Suryanto (2019).

Gambar 2. Rancangan Topologi Akhir

Sesuai dengan rancangan skema jaringan usulan yang ditawarkan maka dengan adanya penggantian Router dimana jalur layan internet dari ISP yang sebelumnya terpisah yang masing-masing terhubung pada router yang terpisah maka pada skema jaringan usulan dibuat menjadi 1 layanan namun kecepatan koneksi kedua layanan sebelumnya digabungkan sehingga paket layanan internet dari ISP menjadi dedicated line $6 \mathrm{Mbps}$ dan terhubung langsng kepada 1 router.

Pada gambar 2 dapat terlihat jalur internet yang didapat dari ISP hanya 1 jalur yang masuk kedalam router namun demikian didalam jaringan tersebut terdapat 2 jalur yang berbeda sebaga pemisah antara jaringan LAN Kantor sekretariat AAUI dengan Layanan Wireless Internet Aula Pusat Pengembangan SDM Asuransi Indonesia.

\section{Rancangan Skema Jaringan}

Sesuai dengan topologi jaringan akhir yang sudah dirancang maka rancangan skema jaringan akhir mejadi seperti terlihat pada gambar 3 .

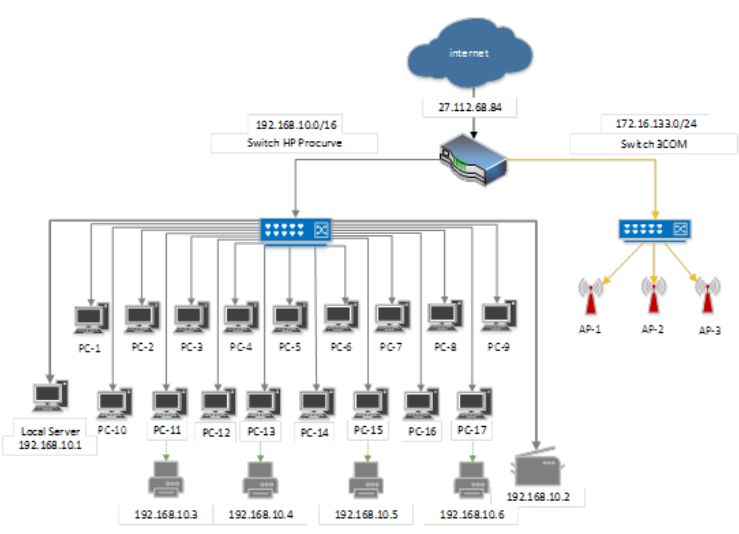

Sumber: Suryanto (2019).
Gambar 3. Rancangan Skema Jaringan Akhir

Pada skema jaringan akhir ini dilakukan penggantian Router dimana jalur layan internet dari ISP yang sebelumnya terpisah yang masing-masing terhubung pada router yang terpisah maka pada skema jaringan usulan dibuat menjadi 1 layanan namun kecepatan koneksi kedua layanan sebelumnya digabungkan sehingga paket layanan internet dari ISP menjadi dedicated line $6 \mathrm{Mbps}$ dan terhubung langsng kepada 1 router.

Tabel 1. Perbandingan Skema Jaringan Awal dengan Skema Jaringan Akhir

\begin{tabular}{|c|c|c|}
\hline & Jaringan Awal & Rancangan Usulan \\
\hline Topologi & $\begin{array}{l}\text { Menggunakan } 2 \text { layanan } \\
\text { Internet dan } 2 \text { router }\end{array}$ & $\begin{array}{l}\text { Menggunakan } 1 \text { layanan } \\
\text { internet dan } 1 \text { router }\end{array}$ \\
\hline $\begin{array}{l}\text { Layanan } \\
\text { Internet }\end{array}$ & $\begin{array}{l}\text { 1. Dedicated line } 2 \mathrm{Mbps} \\
\text { 2. Dedicated line } 4 \mathrm{Mbps}\end{array}$ & Dedicated line $6 \mathrm{Mbps}$ \\
\hline $\begin{array}{l}\text { Keamanan } \\
\text { Jaringan }\end{array}$ & $\begin{array}{l}\text { 1. Mengandalkan Anti Virus } \\
\text { pada setiap perangkat. } \\
\text { 2. Wireless Access Point } \\
\text { Password }\end{array}$ & $\begin{array}{l}\text { 1. Antivirus } \\
\text { 2. Firewall } \\
\text { 3. Hotspot Server } \\
\text { 4. Web login Page }\end{array}$ \\
\hline $\begin{array}{l}\text { Metode } \\
\text { LOGIN }\end{array}$ & $\begin{array}{l}\text { Wifi password langsung } \\
\text { mendapat layanan internet }\end{array}$ & $\begin{array}{l}\text { Web Login page dengan } \\
\text { User ID password } \\
\text { berdasarkan grup } \\
\text { pengguna untuk } \\
\text { mendapat layanan } \\
\text { internet }\end{array}$ \\
\hline
\end{tabular}

Penentuan nama layanan atau Broadcast ID, sesuai keinginan manajemen SSID diberikan nama 'ASURANSI YUU'. Nama ini adalah nama yang akan dibroadcast oleh router agar terbaca oleh calon pengguna untuk terhubung kedalam layanan. Dalam rancangan ini metode yang digunakan adalah hotspot login dengan memasukan user name dan password pada halaman web untuk mendapatkan layanan internet.

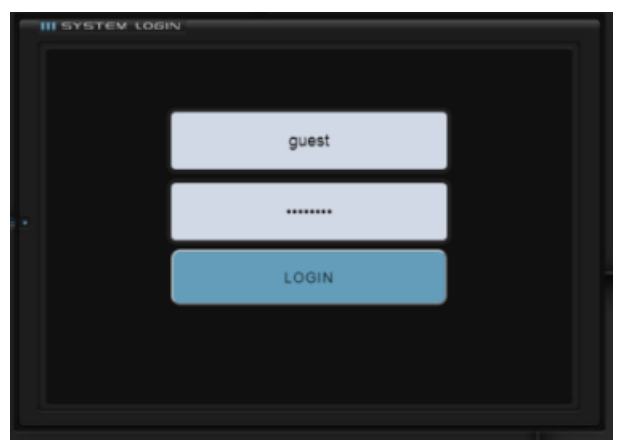

Sumber: Suryanto (2019).

Gambar 4. Halaman Login melalui Browser

Setelah terkoneksi dengan WIFI SSID maka calon pengguna dapat memasukan User ID dan password yang telah diberikan, apabila browser tidak 
otomatis menampilkan halaman tersebut makan dilakukan manual dengan cara menggetikkan alamat 172.16.133.1/login pada kolom address web browser.

Dalam login hotspot ini dibuat 2 grup pengguna dimana setiap grup memiliki ID login dan password yang berbeda. Tujuan pembuatan 2 grup pengguna ini adalah adanya kebutuhan untuk 2 kelompok pengguna yang berbeda yaitu tamu dan

Tabel 2. Tabel Ketentuan Pengguna

\begin{tabular}{ccccccc}
\hline & \multicolumn{1}{c}{} & & $\mathrm{Tx}$ & $\mathrm{Rx}$ \\
\hline \multirow{2}{*}{$\begin{array}{c}\text { ASURANSI YUU } \\
\text { 172.16.133.1 }\end{array}$} & Visitor & guest & tamupsdm & $\begin{array}{c}\text { Internet } \\
\text { limited }\end{array}$ & $2 \mathrm{Mbps}$ & $2 \mathrm{Mbps}$ \\
\cline { 2 - 6 } & Employee & $\mathrm{dpp}$ & aauijkt01 & $\begin{array}{c}\text { Internet \& } \\
\text { LAN }\end{array}$ & $1 \mathrm{Mbps}$ & $1 \mathrm{Mbps}$ \\
\hline
\end{tabular}

Sumber: Suryanto (2019).

Sesuai dengan ketentuan grupnya maka untuk grup visitor, setelah masuk kedalam jaringan hanya dapat menikmati layanan Internet sedangkan untuk grup employee karena ada kebutuhan mengakses dokumen dan printer sharing maka untuk grup pengguna ini selain mendapatkan layanan internet juga dapat mengakses jaringan LAN kantor skretariat AAUI.

Berikutnya adalah memulai proses konfigurasi pada router yang akan digunakan. Konfigurasi dilakukan melalui aplikasi bawaan mikrotik yang bernama winbox dan aplikasi ini berbasis desktop dengan tampilan GUI yang berjalan didalam system operasi Windows.

Router yang dipilih oleh penulis dalam menunjang usulan ini adalah Mikrotik Routerboard RB2011Ui AS-RM. Router inilah yang akan menggantikan fungsi kerja 2 router sebelumnya dimana tetap akan berfungsi sebagai DNS Server serta fungsi lain yang ditambahkan adalah sebagai Hotspot Server untuk layanan Hotspot Aula Pusat Pengembangan SDM Asuransi Indonesia, hotspot server inilah yang akan menjalankan aturan atau ketentuan yang ditetapkan

Setelah selesai dengan pemasangan/instalasi router pengganti ini, selanjutnya melakukan instalasi penulis menjalankan aplikasi ini menggunakan perangkat Laptop berbasis Windows 7, aplikasi Winbox dapat didownload melalui link https://mikrotik.com/download. setelah aplikasi terinstal selanjutnya membuat akun admin untuk masuk kedalam aplikasi dan melakukan konfigurasi dan pengaturan.

Langkah pertama masuk kedalam aplikasi Winbox dengan menggunakan nama pengguna yang telah terdaftar dan yang perlu dilakukan adalah membuat adress list pada router mikrotik yang merupakan pengalamatan untuk setiap port ethernet yang akan digunakan. Disini ether 1 digunakan untuk port dari ISP sebagai layanan internet dengan IP Public 27.112.68.84/29. Kemudian ether 2 dihubungkan dengan swicth untuk Jaringan Internal/LAN kantor sekretariat AAUI dengan menggunakan IP 192.168.10.1/24 dan ethernet karyawan. Sesuai hal tersebut maka diberikan ketentuan serta hak akses yang berbeda pada setiap grup pengguna. Adapun ketentuan yang ditetapkan diatas dilihat pada tabel 2 . 5/bridge 1 yang dihubungkan dengan switch dan Access Point untuk layanan wireles Internet Aula Pusat Pengembangan SDM Asuransi Indonesia.

\begin{tabular}{|l|l|l|l|l|l|l|}
\hline \multicolumn{2}{|c|}{ Address List } & \multicolumn{3}{|c|}{ 口 } \\
\hline
\end{tabular}

Sumber: Suryanto (2019).

\section{Gambar 5. Tab Address List Winbox}

Sebelum membuat Hotspot Server terlebih dahulu dipastikan Internet telah terhubung dengan baik kedalam Router, kemudian dilanjutkan dengan membuat hotpot server dalam winbox dengan langkah-langkah sebagai berikut:

Membuat 2 Jalur dilakukan pada tab Firewall untuk setting firewall, nat, dns, gateway dan ip address. Disini dilakukan pemisahan jaringan antara jaringan internal kantor Sekretariat AAUI dan Layanan Wireless Internet Aula PSDM Asuransi Indonesia.

Instalasi Hotspot server masuk kedalam menu IP dan pilih Hotspot, dimana pengaturan inilah yang menjadi dasar untuk menempatkan ketentuan Hak akses grup yang telah ditetapkan sebelumnya. Dalam hal ini penentuan profile server menggunakan mode System Login dengan alamat default IP 172.16.133.1. 


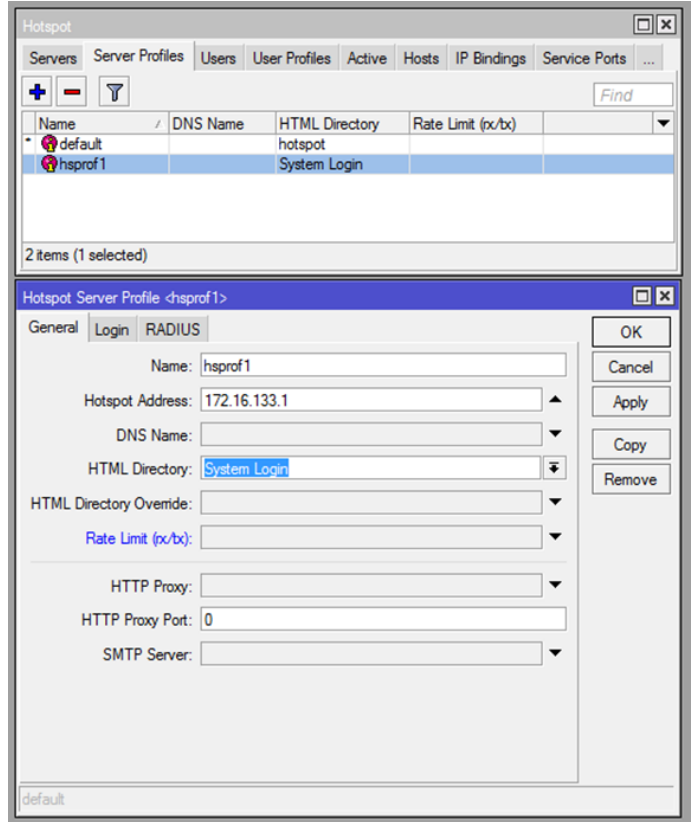

Sumber: Suryanto (2019).

Gambar 6. Konfigurasi Profil Hotspot server Berikutnya dilanjutkan dengann membuat kelompok yang sebelumnya ditetapkan pada table 2 untuk membuat 2 Grup pengguna beserta ketentuan dan hak aksesnya.

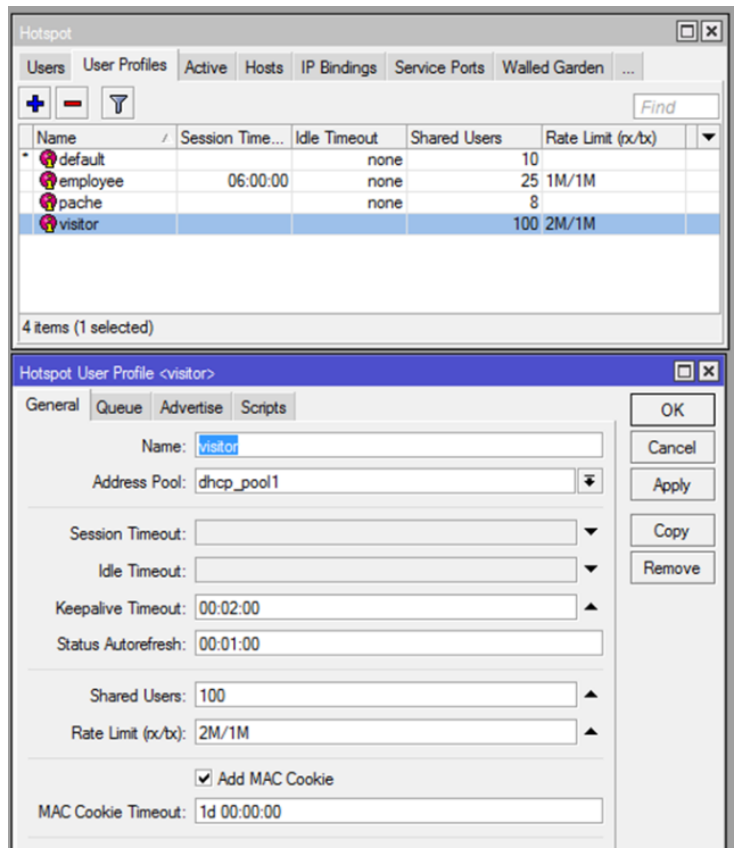

Sumber: Suryanto (2019).

\section{Gambar 7. Konfigurasi Grup Pengguna}

Dari gambar diatas dapat terlihat rincian dari setiap grup pengguna, kita ambil contoh misalnya kelompok employee, dimana disana terlihat untuk kelompok Visitor hanya disediakan maksimum 100 pengguna yang dapat masuk dengan menggunakan akun tersebut dengan rate limit sebesar $2 \mathrm{Mb}$ (rx) dan $1 \mathrm{Mb}(\mathrm{tx})$.
Untuk menetapkan Rate Limit yang diberikan pada setiap grup pengguna dilakukan dengan mengatur "User Profiles", Selain menentukan Rate Limit dapat diatur juga Batas Waktu Koneksi, Jumlah maksimum pengguna dalam sebuah grup. Jumlah maksimum ini apabila pengguna yang terhubung ke dalam salah satu grup melebihi jumlah pengguna yang ditetapkan maka dia tidak akan mendapatkan layanan. Pengaturan ini juga dapat melakukan auto reset untuk pengguna yang dalam waktu tertentu sudah tidak terhubung, dalam MAC cookie timeout disini digunakan $1 \mathrm{~d} / 1$ hari untuk setiap pengguna, maka apabila esoknya ingin kembali terhubung harus melakukan login ulang. Hal ini sangat membantu perangkat untuk membersihkan memory yang terdaftar sehingga tidak perlu dilakukan reset akses point secara manual seperti yang dilakukan sebelumnya.

Setelah selesai dengan pembuatan hotspot server pada router selanjutnya adalah akses kedalam User Manager Mikrotik melalui browser, user manager ini adalah konfigurasi berbasis web yang fungsinya untuk mendaftarkan router yang telah dikonfigurasikan tadi untuk mengaktifkan pengaturannya.

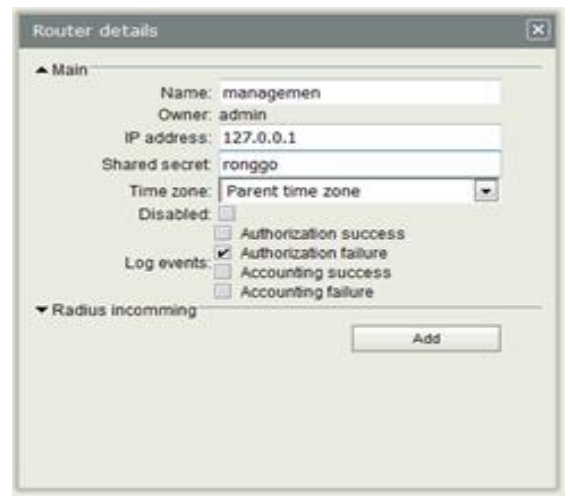

Sumber: Suryanto (2019).

Gambar 8. Registrasi User Manajemen

Untuk membuktikan adanya perubahan atas racangan jaringan akhir ini penulis melakukan pengujian atas koneksi jaringan wireless internet hotspot pada area tersebut, pengujian dilakukan dengan mencoba koneksi dengan menggunakan skema jaringan awal dibandingkan dengan menggunakan skema jaringan akhir.

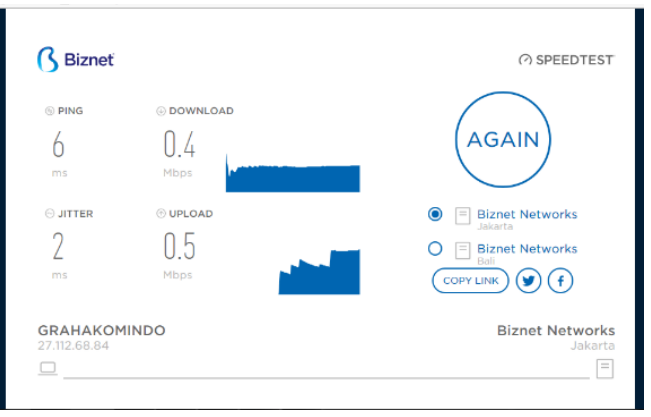


Sumber: Suryanto (2019).

Gambar 8. Pengujian Skema Jaringan Awal Wireless Hotspot pada Pengguna Laptop 1.

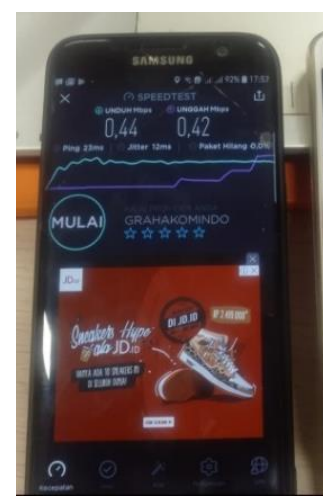

Handpone 1
Sumber: Suryanto (2019).

Gambar 9. Pengujian Skema Jaringan Awal Wireless Hotspot pada Pengguna Handpone

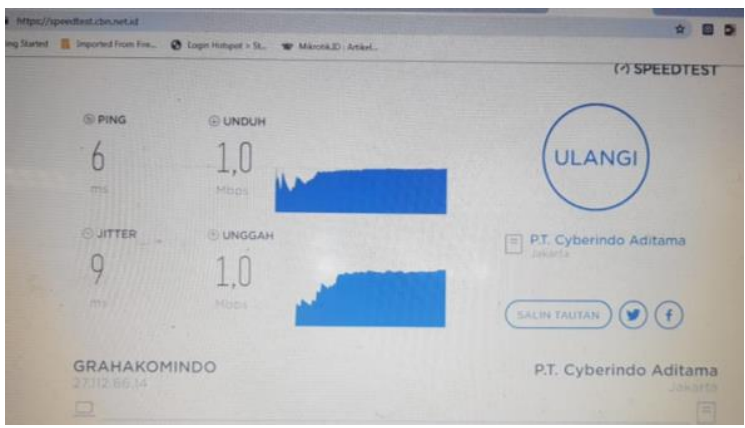

Sumber: Suryanto (2019).

Gambar 10. Pengujian pada Skema Jaringan Akhir pada Wireless Hotspot pada Pengguna Laptop 1.

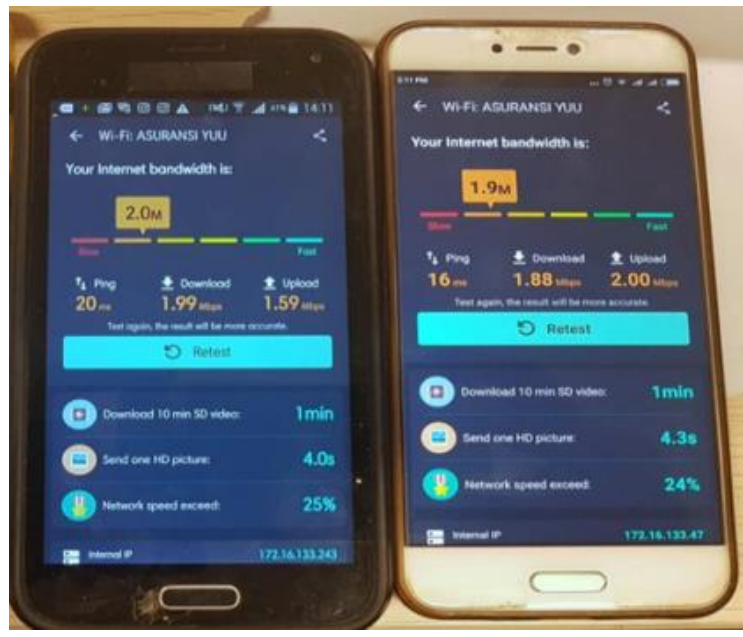

Handpone 1

Handpone 2

Sumber: Suryanto (2019).

Gambar 11. Pengujian Skema Jaringan Akhir Wireless Hotspot pada Pengguna Handpone
Pengujian pada hotspot dengan user group visitor dengan bandwidth 2 Mbps (download) dan 2 Mbps (upload). Melihat hasil tersebut maka penerapan User management dapat menjawab permasalahan yang terjadi pada Aula Pusat Pengembangan SDM Asuransi Indonesia untuk membuat layanan Wireless Internet yang lebih optimal menggunakan speedtest dapat terlihat hasil koneksi antara 2 handpone pada group user visitor dengan menggunakan jaringan wifi yang sama terbukti mendapatkan besaran bandwidth yang hampir sama, begitu juga pada user group employee menggunakan laptop 1 mendapatkan bandwidth 1 Mbps (download) dan 1 Mbps (upload) sesuai dengan pengaturan yang diterapkan.

Tabel 3. Hasil Pengujian Jaringan

\begin{tabular}{|c|c|c|c|}
\hline & Jaringan Awal & \multicolumn{2}{|c|}{$\begin{array}{l}\text { Rancangan Jaringan } \\
\text { Akhir }\end{array}$} \\
\hline Laptop 1 & $6 \mathrm{~ms}$ & Ping & $: 6 \mathrm{~ms}$ \\
\hline (Group & Download (rx) : 0.4 Mbps & Download (rx) & : $1.0 \mathrm{Mbps}$ \\
\hline Employee) & Upload (tx) & Upload (tx) & $: 1.0 \mathrm{Mbps}$ \\
\hline Handphone & $23 \mathrm{~ms}$ & Ping & $: 20 \mathrm{~ms}$ \\
\hline 1 (Group & Download (rx) : $0.44 \mathrm{Mbps}$ & Download (rx) & : $1.9 \mathrm{Mbps}$ \\
\hline Visistor) & Upload (tx) & Upload (tx) & $: 1.5 \mathrm{Mbps}$ \\
\hline Handphone & $7 \mathrm{~ms}$ & Ping & $: 16 \mathrm{~ms}$ \\
\hline 2 (Group & Download (rx) : 0.45 Mbps & Download (rx) & : $1.8 \mathrm{Mbps}$ \\
\hline Visitor) & : $0.61 \mathrm{Mbps}$ & Upload (tx) & : $2.0 \mathrm{Mbps}$ \\
\hline
\end{tabular}

Sumber: Suryanto (2019).

Dari hasil pengujian pada table 3 diatas dan dari skema jaringan akhir maka terlihat beberapa perbedaan dari jaringan awal yaitu penggunaan hanya 1 router, 1 layanan internet (penggabungan 2 koneksi internet menjadi 1), tambahan keamanan jaringan karena ada tambahan firewall, limited waktu koneksi dan metode login yang berbeda dengan wireless login jaringan awal.

\section{KESIMPULAN}

Dari pembahasan dan hasil yang diperoleh, maka implementasi manajemen pengguna pada sebuah layanan hotspot sangat diperlukan untuk dapat menjalankan layanan secara optimal, namun manajemen tersebut harus juga didukung oleh kebijakan/aturan dari penyedia layanan sebagai dasar dalam pengaturan layanan. Sebagai penunjang kemampuan perangkat juga perlu dipertimbangkan agar mampu bekerja secara maksimal melihat kepada seberapa besarnya kebutuhan pelayanan serta banyaknya pengguna layanan.

Dengan menggunakan user manajemen ini dapat menambah sistem keamanan layanan wireless internet yang disediakan, karena dengan adanya model Login User dapat membedakan grup pengguna dan pada setiap grup dapat dibuat ketentuan yang berbeda seperti batas waktu koneksi, maksimum besaran bandwidth bahkan dapat memblokir layanan tertentu. 
Penggunaan user manajemen pada layanan wireless hotspot internet Aula Pusat Pengembangan SDM Asuransi Indonesia dapat menjawab permasalahan yang terjadi pada area tersebut dimana terlihat hasil uji koneksi yang hampir merata dan lebih optimal. Hal tersebut dapat dibuktikan melalui hasil uji coba dengan speedtest.

\section{REFERENSI}

Ardiansa Eko, G. F., Primananda, R., \& Hanafi, M. H. (2017). Manajemen Bandwidth dan Manajemen Pengguna pada Jaringan Wireless Mesh Network dengan Mikrotik. Jurnal Pengembangan Teknologi Informasi Dan Ilmu Komputer, 1(11), 1226-1235.

Athailah. (2013). Mikrotik untuk Pemula. Jakarta: MediaKita.

Ambarwati, R., Saniya Y., \& Priyono, W. A. 2013. Sistem Manajemen Bandwidth dengan Prioritas. Jurnal Penelitian.

Doni, F. R. (2014). Optimalisasi Jaringan Wireless Dengan Router Mikrotik Studi Kasus Kampus Bsi Tangerang. Evolusi, II(1), 37-45.

Pamungkas, C. A. (2016). Manajemen Bandwith Menggunakan Mikrotik Routerboard. Jurnal
INFORMA Politeknik Indonusa Surakarta, 1(3), 17-22.

P. Rawles and J.E. Goldman (2004). Applied Data Communication, A Business-Oriented Approach (fourth ed). New Jersey: John Wiley and Sons.

Primartha, R. (2019). Manajemen Jaringa Komputer (1st ed.). Bandung: Informatika Bandung.

Rifai, B. (2017). Management Bandwidth Pada Dynamic Queue Menggunakan Metode Per, 2(2), 73-79.

Rifai, B., \& Sudibyo, A. (2018). Manajemen Wireless Access Point Pada Hotspot Server. Jurnal PILAR Nusa Mandiri, 14(1), 111-116.

Sofana, I. (2013). Membangun Jaringan Komputer (1st ed.). Bandung: Informatika Bandung.

Sugiyono. (2013). Metode Penelitian Kuantitatif Kualitatif dan R \& D. Bandung: Alfabeta

Suryanto. (2019). Laporan Akhir Penelitian Mandiri. Jakarta: Universitas Bina Sarana Informatika 